\title{
INFLUENCE OF THE LOADING RATE ON THE CONCRETE CONE FAILURE
}

\author{
J. OŽBOLT \\ Institute of Construction Materials, University of Stuttgart, 70550 Stuttgart, Germany
}

\begin{abstract}
In the present paper the rate sensitive model, which is based on the energy activation theory of bond rupture, and its implementation into the M2-O microplane model for concrete are discussed. It is first demonstrated that the new model realistically predicts the influence of the loading rate on the uniaxial compressive behaviour of concrete. The new rate sensitive microplane model is then applied in a 3D finite element study of the pull-out of the headed stud anchors from a concrete block. In the study the influence of the loading rate on the pull-out capacity and on the size effect are investigated. The anchors are loaded with relatively high loading rates. The results of the study show that with the increase of the loading rate the nominal pull-out resistance increases. Moreover, it has been found that the size effect on the concrete cone capacity is stronger when the loading rate is higher. The result of numerical study implies that it must exist a problem dependent critical loading rate for which the size effect is minimal.
\end{abstract}

\section{INTRODUCTION}

It is well known that the loading rate influence significantly structural response. The material response depends on the loading rate through influence two different effects: (1) through the rate dependency of the growing microcracks and (2) through the creep of the bulk material between the cracks. Depending on the material, it dominates the first or the second effect. For quasibrittle materials, such as a concrete, which exhibit cracking and damage phenomena the first effect dominates for very high loading rates (impact loading). This is especially thru for the case of recently observed phenomena (Bažant et al. [1]) for which a sudden increase of the loading rate in softening leads to reversal of softening into hardening. However, for lower loading rates the second effect is more important.

In the literature can be found a number of theoretical and experimental studies that deal with the problem of the rate effect for different materials (for literature review see Bažant et al. [1]). In most of these studies various stress-displacement relations, similar to the spring-dashpot models of viscoelasticity, were used. However, as pointed out by Bažant et al. [1] these models performs well only for one order of magnitude of the loading rate. Here is for the rate dependency of the crack propagation adopted a model, which is applicable over many orders of magnitude of the loading rate. The model is based on the rate process theory (Krausz and Krausz [2]) of bond ruptures. It is coupled with the M2-O microplane model for concrete (Ožbolt et al. [3]), which has been shown to be capable to realistically simulate failure of concrete structures for complex threedimensional stress-strain states (Ožbolt [4]).

Experience, a large number of experiments as well as numerical studies for anchors of different sizes confirm that fastenings are capable to transfer a tension force into a concrete member without using reinforcement (Eligehausen et al. [5]). Provided the steel strength of the anchor is high enough, a headed stud subjected to a tensile load normally fails by cone shaped concrete breakout. Experimental and theoretical investigations clearly show that for the pull-out problem cracking of concrete is an important aspect of the resistance mechanism. In contrast to a number of structures, which rely only on the material strength, the concrete cone resistance relies mainly on the energy consumption capacity of concrete that is directly related to the concrete 
cracking. Since cracking is time phenomena, it is important to know how the loading rate influences the concrete pull-out capacity. Moreover, the concrete cone resistance exhibits significant size effect on the ultimate load. The size effect can be well predicted by the size effect formula that is based on LEFM (Ožbolt [4]). Presently there is no experimental and theoretical investigation in which the size effect on the concrete cone capacity is systematically investigated for different loading rates. It is known that for the long term loading (very low loading rates), in which creep of concrete plaies important role, the size effect becomes stronger compared to the normal loading rates. Therefore, it would be interesting to investigate how relatively fast loading, where creep of concrete is of a minor importance, influences the size effect. This is here investigated on the example of the pull-out of a headed stud anchor from a concrete block. The small strain formulation of the new rate dependent M2-O microplane model is used. In the study the inertial forces are neglected, i.e. the analysis was static.

\section{RATE DEPENDANCY IN THE M2-O MICROPLANE MODEL}

Similar to the formulation proposed by Bažant et al. [1] the rate dependency in the present M2-O microplane model (Ožbolt et al. [3]) consists of two parts: (1) the rate dependency related to the formation of the microcracks and (2) the rate dependency due to the creep of concrete between the microcracks. In the here presented model the rate dependency related to the formation of the microcracks is responsible for the rate dependent softening and for the rate dependent hardening, i.e. for the initial dynamic elasticity modulus of concrete. The reason for this is the assumption that the microcracks start to grow immediately after the application of load. Consequently, unlike to the model proposed by Bažant et al. [1] in which is the initial elasticity modulus controlled only by a simple viscoelastic model, the initial (secant) elasticity modulus is here controlled by the rate of growth of microcracks. The second part of the rate dependency, in which the creep of concrete plaies important role, is controlled by the generalized Maxwell model for concrete (Ožbolt and Reinhardt [6]). The first part of the rate dependency is responsible for the short time loads, up to duration of one hour, and the second part of the model is responsible for the long term loading. The discussion related to the second part of the model is out of the scope of the present paper. For more detail see Ožbolt and Reinhardt [6].

The rate of strain $d \varepsilon / d t$ in a continuum with a number of parallel cohesive cracks, which may be imagined to represent macroscopic strain softening, can be expressed as:

$$
\frac{d \varepsilon}{d t}=\frac{\dot{w}}{s_{C r}}+\frac{\dot{\sigma}}{E} \approx \frac{\dot{w}}{s_{C r}}
$$

where $\varepsilon$ = average macroscopic strain normal to the direction of parallel cracks, $s_{c r}=$ spacing of the parallel cracks, $E=$ Young's modulus of bulk material and $(d \sigma / d t) / E$ is the elastic strain ratio which can be, compared to the crack opening ration $d w / d t$, neglected. After introducing a few realistic simplifications into the concept that is based on the activation energy theory (Bažant et al. [1]), the influence of the rate effect on the rate independent stress-strain relation $\sigma(\varepsilon)$ can be written as:

$$
\sigma(\varepsilon)=\sigma^{0}(\varepsilon)\left[1+C_{2} \ln \left(\frac{2 \dot{\varepsilon}}{C_{1}}\right)\right]
$$

where $C_{1}$ and $C_{2}$ are constants that have to be obtained by the fit of test data. 
In the M2-O microplane model the macroscopic response is obtained by integrating normal and shear microplane stresses over all microplanes. The rate independent microplane stress components $\sigma_{M}^{0}\left(\varepsilon_{M}\right)$ ( $M=$ stays for microplane volumetric, deviatoric and shear component, respectively) are calculated from the known microplane strains $\varepsilon_{M}$ using in advance defined microplane uniaxial stress-strain constitutive relationships (Ožbolt et al. [3]). It seems reasonable to assume that the rate effect on each microplane component is of the same type as given by eqn. (2). Consequently the rate dependency for each microplane component reads (Bažant et al. [1]):

$\sigma_{M}\left(\varepsilon_{M}\right)=\sigma_{M}^{0}\left(\varepsilon_{M}\right)\left[1+c_{2} \ln \left(\frac{2 \dot{\gamma}}{c_{1}}\right)\right] \quad$ with $\quad \dot{\gamma}=\sqrt{\frac{1}{2} \dot{\varepsilon}_{i j} \dot{\varepsilon}_{i j}} \quad c_{1}=\frac{c_{0}}{s_{C r}}$

a)

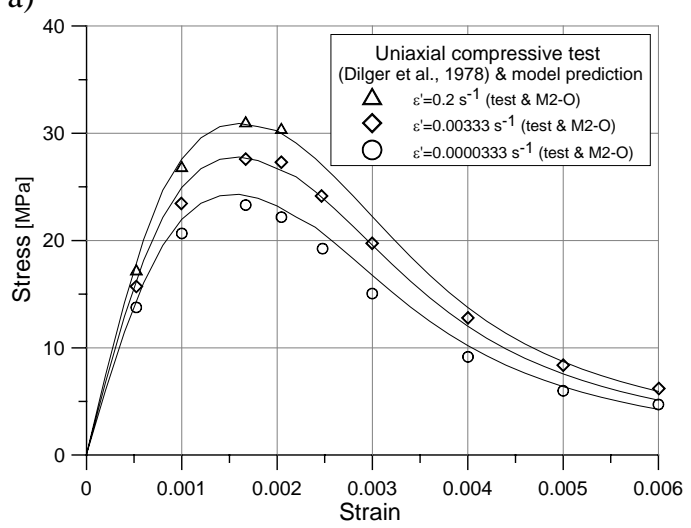

b)

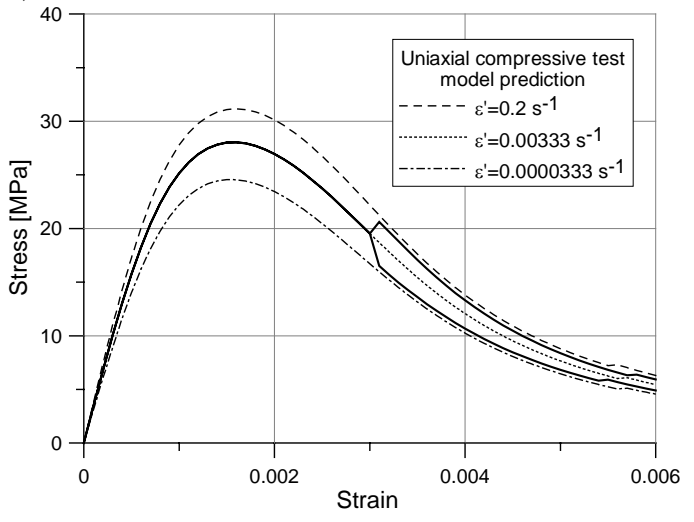

Figure 1: Uniaxial compressive test: (a) model prediction and test data (Dilger et al. [7]) and (b) model prediction - increase and decrease of the loading rate in the softening region.

a)

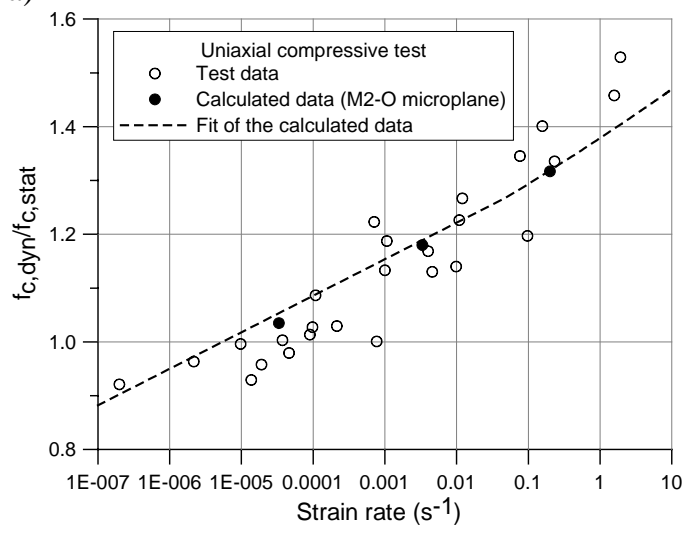

b)

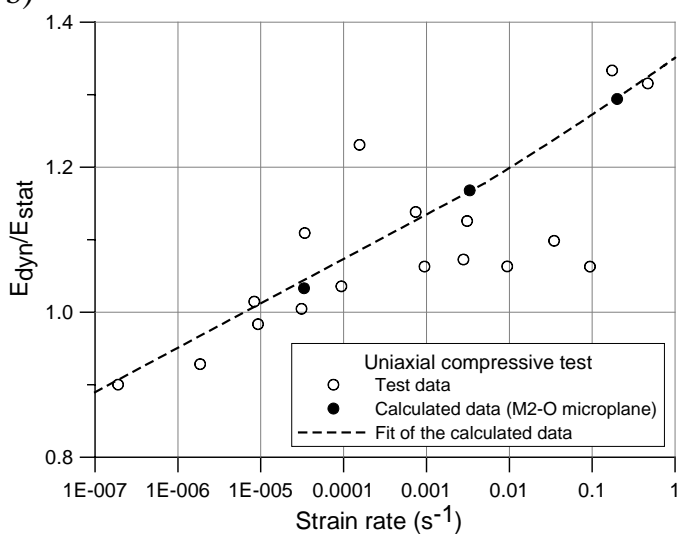

Figure 2: Uniaxial compressive test: (a) rate dependent compressive strength - test data and model prediction and (b) rate dependent initial Young's modulus - test data and model prediction. 
where $c_{0}$ and $c_{2}$ are material rate constants which have to be calibrated by fitting of the test data, $\dot{\varepsilon}_{i j}=$ components of the macroscopic strain rate tensor (indicial notation). From eqn. (3) is obvious that the rate magnitude is not measured on the individual microplanes, which would be not objective, but on the macroscale (Bažant et al. [1]). Furthermore, in the M2-O microplane model eqn. (3) applies on all microplane components except on volumetric compression, which is assumed to be rate insensitive. The reason is the fact that in case of volumetric compression there is no crack development since the material is compacted.

The above model parameters are calibrated by the uniaxial compressive tests performed by Dilger et al. [7]. The tests have been carried out for three loading rates: $0.2 s^{-1}, 3.33 E-3 s^{-1}$ and 3.33E-5 $s^{-1}$. Assuming average crack spacing of $s_{c r}=100 \mathrm{~mm}$, from the calibration procedure follows: $c_{0}=0.0004$ and $c_{2}=0.032$. Using these parameters the uniaxial rate dependent constitutive relationship obtained from the microplane model is for three different loading rates plotted in Figure 1. In the same Figure the test results are plotted as well. As can be seen, the agreement is good. The influence of the rate effect on the uniaxal compressive strength and initial Young's modulus is plotted in Figure 2. In both figures the static strength and the static Young's modulus correspond to the strain rate of $1.0 \mathrm{E}-5 \mathrm{~s}^{-1}$ for which the average test value of the ratio between dynamic and static strengths is equal to one. As can be seen, the microplane model prediction agrees well with the average trend observed in the experiments.

\section{INFLUENCE OF THE LOADING RATE ON THE CONCRETE CONE FAILURE}

To investigate the influence of the loading rate on the concrete cone failure, a headed stud anchor is pulled out from a concrete block. The edge distance was chosen such that an unrestricted cone formation was possible. The geometry of the headed studs was such that the pressure under the head of the stud at peak load was relatively low (2 to 3 times the uniaxial compressive strength of concrete), i.e. the heads were relatively large and they were not scaled in proportion to the embedment depth. Such anchors have recently been used in the tests performed by KEPRI \& KOPEC [8] and they are often used in the nuclear power plants. The load was applied by controlling displacement $\delta$ of the stud. Three embedment depths were considered $\left(h_{e f}=150,890\right.$ and $1500 \mathrm{~mm}$ ) and for each size the three loading rates were applied: $d \delta / d t=0,5$ and $20 \mathrm{~mm} / \mathrm{sec}$. The geometry of the specimen and a typical finite element mesh are shown in Fig. 3. The concrete properties are taken as: Young's modulus $E_{C}=28000 \mathrm{MPa}$, Poisson's $v_{C}=0.18$, tensile strength $f_{t}=2.5 \mathrm{MPa}$, uniaxial compressive strength $f_{c}=30 \mathrm{MPa}$ and concrete fracture energy $G_{F}=0.08$ $\mathrm{N} / \mathrm{mm}$. The behaviour of steel was assumed to be linear elastic with Young's modulus $E_{S}=200000 \mathrm{MPa}$ and Poisson's ratio $v_{S}=0.33$. In the 3D finite element analysis (FE) four nodes solid elements were used. To eliminate mesh sensitivity 3D FE analysis was carried out using crack band approach (Bažant and Oh [9]).

The typical concrete cone failure mode is shown in Figure 3b. Figure 4a shows the relative pull-out resistance for all three embedment depths as a function of the loading rate. The static resistance for $h_{e f}=150 \mathrm{~mm}$ is taken as a reference value. It can be seen that by increasing loading rate the nominal strength increases. The largest increase is obtained for the smallest embedment depth whereas for relative large embedment depths $\left(h_{e f}=890\right.$ and $1500 \mathrm{~mm}$ ) the loading rate influence is almost identical, however, it is much smaller than for $h_{e f}=150 \mathrm{~mm}$. The reason is probably due to the fact that for small embedment depth the size of the fracture process zone is relative to the embedment depth large what leads to stronger influence of the loading rate on the failure load.

The influence of the loading rate on the size effect is shown in Figure 4b. Plotted is the nominal pull-out strength $\sigma_{N}=P_{U} /\left(h^{2}{ }_{e f} \pi\right)$ and fitted by the Bažant's size effect formula (Bažant [10]). As shown by previous numerical and experimental studies, the size effect on the static concrete cone pull-out is relatively strong and close to the prediction according to LEFM (Ožbolt [4]). Comparing results shown in Figure $4 \mathrm{~b}$ for different loading rates it can be seen that by increase of the loading rate the size effect becomes stronger. The reason is the fact that for high 
loading rates the increase of the nominal strength is larger for smaller embedment depth (see Fig. 4a). This effect is just opposite to the cases where the concrete structures are loaded by relatively low loading rates for which the interaction between creep and fracture causes stronger size effect. Therefore, if the presented results are correct it can be concluded that a problem dependent critical loading rate for which the size effect is minimal must exist. If the loading rate is larger or smaller than the critical one, the size effect increases. For the first case the creep-fracture interaction dominates and for the second case the rate dependency is controlled by the growing microcracks.

a)
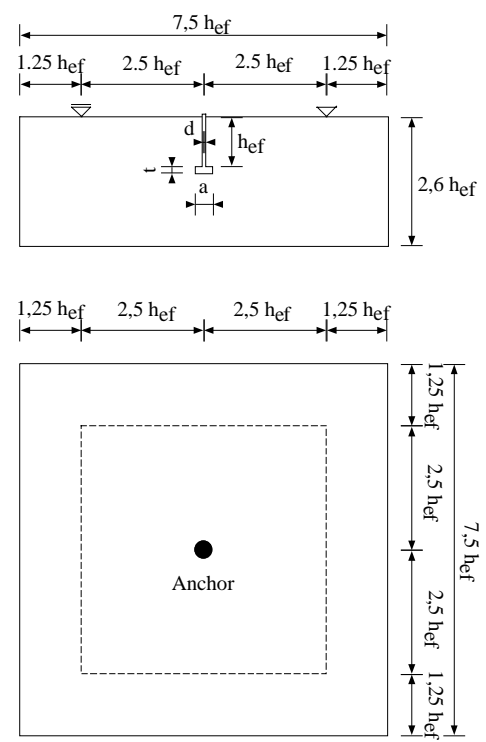

b)

\begin{tabular}{llll}
\hline \hline$h_{e f}[\mathrm{~mm}]$ & $d$ & $t$ & $a$ \\
\hline \hline 150 & 16 & 17 & 40 \\
889 & 95.3 & 102 & 216 \\
1500 & 160.8 & 169 & 311 \\
\hline \hline
\end{tabular}

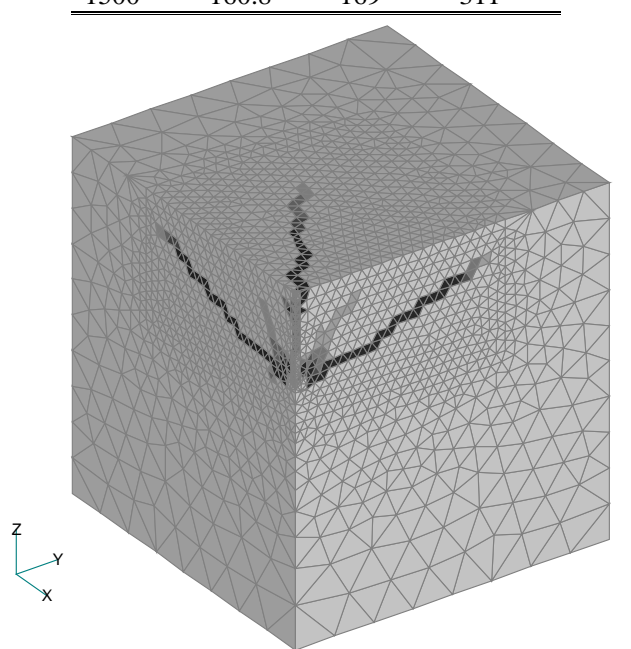

Figure 3: Investigated pull-out geometry: (a) analysis set-up and (b) geometrical data and typical finite element mesh \& failure mode for $h_{e f}=150 \mathrm{~mm}$ ( $1 / 4$ of the specimen).

a)

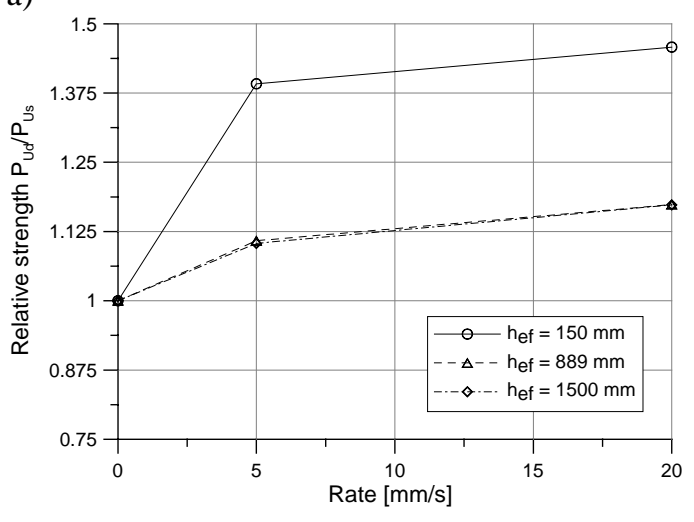

b)

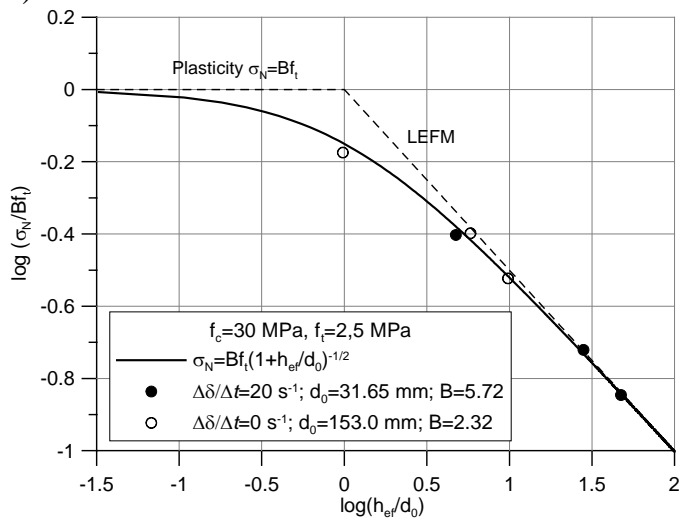

Figure 4: (a) Relative pull-out strength versus loading rate; (b) Fit of the calculated data by the Bažant's size effect formula. 


\section{CONCLUSIONS}

In the present paper the rate sensitive model, which is based on the energy activation theory of bond rupture, and its implementation into the M2-O microplane model are discussed. The comparison between model prediction and test data obtained for the uniaxial compression shows that the model realistically predicts the influence of the loading rate on the compressive strength. Using the new rate sensitive microplane model the parametric study for the pull-out of the headed stud from a concrete block was carried out. In the static 3D finite element analysis the influence of the loading rate on the pull-out capacity and on the size effect were investigated. The results show that with increase of the loading rate the nominal pull-out resistance increases. Furthermore, the size effect on the concrete cone capacity increases with increasing loading rate, i.e. the reduction of the nominal strength is larger if the loading rate is higher. It is known that for very low loading rates the size effect is stronger if the loading rate is lower. Therefore, from the result of the study it can be concluded that a problem dependent critical loading rate exists for which size effect is minimal. When the loading rate is larger or smaller than the critical one, the size effect is stronger. Further experimental and numerical investigations are needed to confirm the results of the study.

\section{REFERENCES}

[1] Bažant, Z. P., Caner, F.C., Adley, M. D. and Akers, S. A. (2000). Fracturing rate effect and creep in microplane model for dynamics. Journal of Engineering Mechanics, ASCE, 1126(9), 962-970.

[2] Krausz, A. S. and Krausz, K. (1988). Fracture kinetics of crack growth, Kluwer, Dordrecht, The Netherlands.

[3] Ožbolt, J., Li, Y.-J. and Kožar, I. (2001). Microplane model for concrete with relaxed kinematic constraint. International Journal of Solids and Structures. 38: 2683-2711.

[4] Ožbolt, J. (1995). Size effect in concrete and reinforced soncrete structures. Postdoctoral Thesis, University of Stuttgart, Germany.

[5] Eligehausen, R. Mallee, R. and Rehm, G. (1997). Befestigungstechnik, Ernst \& Sohn, Berlin, Germany.

[6] Ožbolt, J. and Reinhardt, H.W. (2002). Numerical study of mixed mode fracture in concrete. International Journal of Fracture, 118, 145-161.

[7] Dilger, W.H., Koch, R. and Kowalczyk, R. (1978). Ductility of plained and confined concrete under different strain rates. American Concrete Institute, Special publication, Detroit, Michigen, USA.

[8] KEPRI \& KOPEC (2003). Internal Report on: Pre-tests for Large-sized Cast-in-place Anchors. South Korea.

[9] Bažant, Z. P., and Oh (1983). Crack band theory for fracture of concrete. RILEM, 93(16), 155-177.

[10] Bažant, Z. P.(1984). Size effect in blunt fracture: Concrete, Rock, Metal. Journal of Engineering Mechanics, ASCE, 110(4), 518-535. 